\title{
Water turnover rates in sedentary and exercising middle aged men
}

\author{
J B Leiper, A Carnie, R J Maughan
}

\begin{abstract}
Objective-To assess the effect of exercise on water turnover in endurance trained middle aged men.

Methods-Water turnover was assessed using ${ }^{2} \mathrm{H}_{2} \mathrm{O}$ as a tracer for water in six exercising and six sedentary middle aged men over seven consecutive days. The exercising subjects ran on average $14.8 \mathrm{~km}$ per day, while the sedentary group did not take part in any regular physical activity. Results-The average median (range) rate of water turnover $\left(\mathrm{ml} \cdot \mathrm{d}^{-1}\right)$ was higher in the exercising group [4673 (4320 to 9606)] than in the sedentary group [3256 (2055 to 4185$) ; P=0.001]$. Although there was a tendency for non-renal water losses $\left(\mathrm{ml} \cdot \mathrm{d}^{-1}\right)$ to be greater in the exercising group [1746 (1241 to 5196)] than in the sedentary group [1223 (1021 to 1950); $\mathbf{P}=0.08$ ], the major difference in water loss between the groups was the greater urine output $\left(\mathrm{ml}^{\left.-\mathrm{d}^{-1}\right)}\right.$ in those who exercised [3021 (2484 to 4225)] compared to those who were sedentary [(1883 (925 to 2266); $P=0 \cdot 001$ ].
\end{abstract}

Conclusions-The results suggest that fluid intake in middle aged men who exercise regularly must be greater than that of sedentary individuals of the same age group, and that the difference in volume is in excess of that required to replace exercise induced sweat and respiratory water losses.

(Br F Sports Med 1996;30:24-26)

Key terms: body water; exercise; urination

Water balance in healthy individuals is maintained relatively constant on a daily basis by a complex series of interrelated factors which control intake and output of both water and electrolytes. ${ }^{12}$ There is a continuous loss of water from the skin and respiratory tract, and intermittent losses from the kidneys and gastrointestinal tract. The kidneys regulate water excretion in excess of the obligatory urine loss. Water intake occurs in the form of food and drink, with the sensation of thirst controlling the fluid intake. Control of body hydration is therefore a balance between the stimulus of thirst and urine output. Physical exercise of sufficient intensity and duration will induce sweat production, even in cool environments, which will cause a loss of body water that must be replaced if euhydration is to be maintained. The effect of exercise on water turnover in endurance trained middle aged men was examined using deuterium oxide $\left({ }^{2} \mathrm{H}_{2} \mathrm{O}\right)$ as a tracer for water.

\section{Methods}

Six endurance trained and six sedentary healthy male subjects gave their informed consent to participate in the study which had the approval of the local ethics committee. All subjects were in approximate steady state with respect to body mass and physical activity patterns. The endurance trained subjects were recreational runners who regularly competed in races at distances of $10 \mathrm{~km}$ or more. The endurance trained men formed the exercising group and had a mean(SD) age of $41(6)$ years, height of $1.73(0.05) \mathrm{m}$, and body mass of $63 \cdot 8(7 \cdot 3) \mathrm{kg}$. Subjects in the sedentary group were matched to the exercising group with respect to age [42(7) years; $P=0.75]$, height $[1.74(0.06) \mathrm{m} ; \mathrm{P}=0.83]$, and body mass $[71 \cdot 3(10 \cdot 9) \mathrm{kg} ; P=0 \cdot 19]$. During the study subjects were requested to maintain their normal pattern of exercise, eating, drinking, and daily lifestyle. Two of the exercising group subjects each had one rest day during the $7 \mathrm{~d}$ study period and the mean (range) daily distance run by individuals in this group was $14.8(0-36 \cdot 5) \mathrm{km}$, with the mean total weekly distance run being $103(68-148) \mathrm{km}$. Subjects in the sedentary group undertook less than $60 \mathrm{~min}$ of strenuous exercise over the study period. The study was carried out in May and June when the mean (range) maximum daytime temperature was $14(7-21){ }^{\circ} \mathrm{C}$ and the weather was mainly cloudy with rain.

On one evening before retiring to bed, subjects micturated, then ingested 10.0004 (0.0003) $\mathrm{g}$ of ${ }^{2} \mathrm{H}_{2} \mathrm{O}(99.9 \%$; Sigma) which was diluted with a drink of their choice. Subjects were instructed to rinse the container of ${ }^{2} \mathrm{H}_{2} \mathrm{O}$ several times and to ingest the contents. An aliquot of the next urine passed was collected, its volume determined, and the deuterium $\left({ }^{2} \mathrm{H}\right)$ concentration measured. In all cases this sample was passed in the morning and was therefore collected more than $6 \mathrm{~h}$ after ingestion of the ${ }^{2} \mathrm{H}_{2} \mathrm{O}$. The remainder of the urine passed at this time and all the urine excreted until the subject next retired to bed was collected and pooled. Twenty four hour urine collection was continued over a total of seven consecutive days. Essentially the method of Lukaski and Johnson ${ }^{3}$ was used to determine the ${ }^{2} \mathrm{H}$ concentration of the aqueous phase of the morning urine samples by infrared spectroscopy. Total body water volume of each subject was calculated from the ${ }^{2} \mathrm{H}$ concentration measured in the first morning urine 
sample using the formula of Halliday and Miller, ${ }^{4}$ and the ${ }^{2} \mathrm{H}$ concentration in the subsequent morning samples was used to estimate daily water turnover assuming that total body water, at this time of day, remained constant for each subject.

The total daily urine output including the sample volume used for ${ }^{2} \mathrm{H}$ measurement was recorded. The daily non-urine water loss was estimated as the difference between the calculated water turnover for that day minus the volume of urine excreted over the same period.

Data were initially tested for normality of distribution by correlation of $\mathrm{n}$ scores and were then analysed using a one way analysis of variance followed by Tukey's multiple range test or Kruskal-Wallis test and by the Wilcoxon matched pairs signed rank test where appropriate. Values are given as mean(SD).

\section{Results}

Mean total body water volume of the exercising group [39.3(4.9) litres] was similar to that of the sedentary group [39.9(3.9) litres; $P=$ $0 \cdot 80)$. However, expressed as a percentage of body mass total body water content was greater in the exercising group $[62 \cdot 8(3.6) \%]$ than in the sedentary group $[55 \cdot 5(6.4) \% ; \mathrm{P}=0.037]$, reflecting differences in body fat content.

Body water turnover rate was faster in the exercising group than in the sedentary group $(P=0.001)$ (figure), the average daily median rate being 4673 (range 4320 to 9606 ) and 3256 (2055 to 4185$) \mathrm{ml} \cdot \mathrm{d}^{-1}$ respectively. Average water turnover rates each day were fairly constant in the exercising group $(P=0.33)$ and in the sedentary group $(P=0 \cdot 17)$. The average daily urinary loss $\left(\mathrm{ml} \cdot \mathrm{d}^{-1}\right)$ was greater in the exercising group [3021 (2484 to 4225)] than in the sedentary group [1883 (925 to 2266); $\mathrm{P}=0.001]$. Daily urine loss was rather constant in the exercising group $(P=0.85)$ and in the sedentary group $(P=0 \cdot 88)$. The calculated average non-urine daily water loss $\left(\mathrm{ml} \cdot \mathrm{d}^{-1}\right)$ tended to be greater in the exercising group [1746 (1241 to 5195)] than in the sedentary group [1223 (1021 to 1950)], but no differences could be detected $(P=0 \cdot 08)$. One subject in the exercising group, who produced

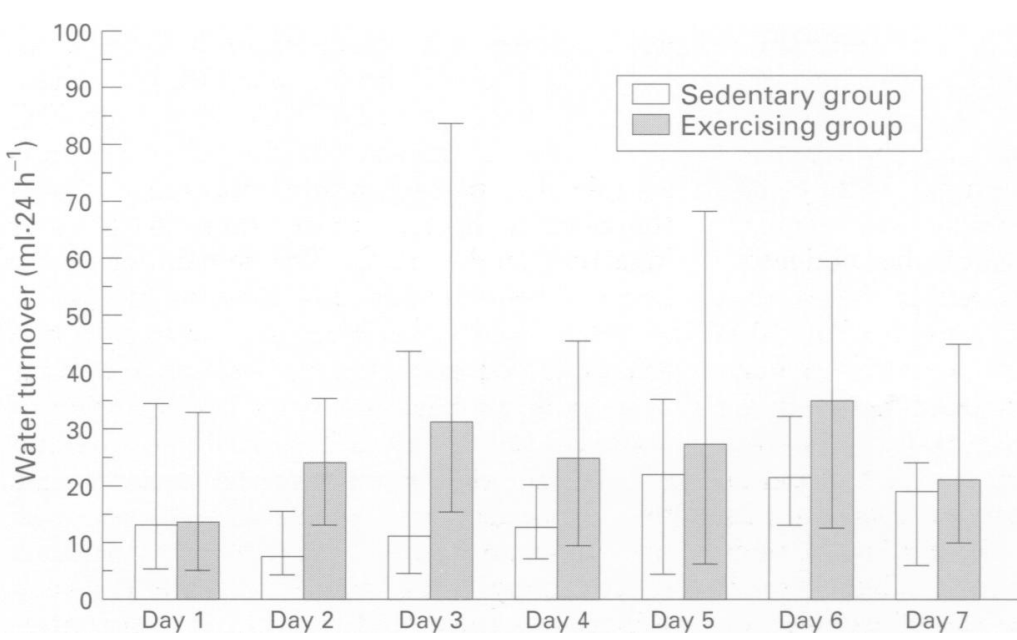

Calculated daily water turnover rates $\left(\mathrm{ml} \cdot 24 \mathrm{~h}^{-1}\right.$; median and range) for the two groups. the highest average daily water turnover value $\left[9606(4328) \mathrm{ml} \cdot \mathrm{d}^{-1}\right]$, excreted urinary volumes [5786 (2817 to 6290$) \mathrm{ml} \cdot \mathrm{d}^{-1}$ ] which were greater than that produced by the other subjects in that group $(P=0.001)$. However, excluding this subject's data had little effect on the differences between the two groups in water turnover $(P=0.008)$ or urinary excretion $(P=0.002)$ rates.

\section{Discussion}

Although the doubly labelled water technique implicitly estimates body water turnover when used to measure energy expenditure, ${ }^{5}$ investigators do not publish the water turnover values, and there is a paucity of information regarding water turnover rates in physically active individuals. The use of a tracer for estimating body water turnover eliminates the need to measure total dietary water intake and metabolic water production over the study period. Due to the exchange of deuterium with labile hydrogen of proteins and other body constituents, total body water and water turnover are overestimated by between one and five per cent using the ${ }^{2} \mathrm{H}$ dilution technique. ${ }^{6}$ In the present study, the initial overnight equilibration time might be expected to increase the likelihood of overestimating total body water, but others ${ }^{7}$ have shown that estimation of total body water by ${ }^{2} \mathrm{H}$ dilution and densitometry were similar $(P=0.43)$ when the deuterium tracer equilibrated overnight, and that greater differences between the methods were detected when the equilibration times were between four and six hours.

This study suggests that middle aged men who regularly undertake prolonged exercise have a water turnover rate which is faster than that of sedentary individuals of the same age group. Physiological textbooks typically give values for body water turnover of between 2500 and $3000 \mathrm{ml} \cdot \mathrm{d}^{-1}$ for sedentary men, ${ }^{8}$ but emphasise that there is great daily and individual variation. The average daily water turnover rate of $3256 \mathrm{ml}$ in the sedentary subjects in the present study was similar to that of the upper values quoted.

There was a trend for non-renal water loss to be greater in the active than the sedentary group $(P=0.08)$, presumably reflecting the fraction of water loss caused by exercise induced sweat and respiratory losses. Normal daily insensible water loss in resting man has been shown to be approximately $1000 \mathrm{ml} \cdot \mathrm{d}^{-1}$ which, when adjusted for body surface area, ${ }^{9}$ gives an value of $30 \mathrm{ml} \cdot \mathrm{m}^{-2} \cdot \mathrm{h}^{-1} .810$ This figure is close to the average non-renal water loss of the sedentary group $\left(1223 \mathrm{ml} \cdot \mathrm{d}^{-1}\right.$, $\left.28 \mathrm{ml} \cdot \mathrm{m}^{-2} \cdot \mathrm{h}^{-1}\right)$ in the present study. The exercising group ran on average $14.8 \mathrm{~km}$ in approximately 60 minutes each day. Although no direct measurement was made of exercise induced sweat loss of the exercising group, the apparent difference of $523 \mathrm{ml}$ in non-renal water loss between the exercising group and sedentary group is similar to the mean sweat loss of $680 \mathrm{ml} \cdot \mathrm{h}^{-1}$ recorded in a group of men cycling at $70 \%$ of their $\dot{\mathrm{VO}}_{2}$ max in an environmental temperature of $10^{\circ} \mathrm{C}$ (Galloway S G, 
unpublished results). It appears therefore that the lack of a clear difference in non-renal water loss between the sedentary group and exercising group was because the thermal stress of running was inadequate to stimulate sufficient sweat loss in the cool $\left(14^{\circ} \mathrm{C}\right)$ conditions which prevailed during the study.

Perhaps surprisingly, the main difference between the groups was an increased urinary output from the men who were exercising. Dietary intake was not measured in this study, but fluid intake in the exercising group must have exceeded that of the sedentary group. Physiological and psychological factors play equally important roles in determining the volume of beverages consumed by humans. Differences in fluid intake between the two groups may have been due solely to differences in the social drinking habits of the volunteers. However, the difference might have been due to exercise induced dehydration stimulating the sensation of thirst, which may not be satisfied if inappropriate amounts of electrolytes are supplied with the drinks and diet. Alternatively, regular bouts of dehydration occurring over several years may habituate the individual to ingest a fluid intake in excess of his physiological requirement. ${ }^{11}$ The explanation may simply be that promotion, by advertisements and articles in running magazines, of the need for athletes to maintain their hydration has heightened the awareness of the exercising subjects of the need to drink, leading to a conscious effort to increase intake. ${ }^{11} 12$

1 Greenleaf JE. Problem: thirst, drinking behaviour, and involuntary dehydration. Med Sci Sports Exerc 1992; 24:645-56.

2 Gregersen MI, Rawson RA. Blood volume. Physiol Rev 1959;39:307-42.

3 Lukaski HC, Johnson PE. A simple, inexpensive method of determining total body water using a tracer dose of $\mathrm{D}_{2} \mathrm{O}$ and infrared absorption of biological fluids. $\mathrm{Am} \mathcal{f} \mathrm{Clin}$ and infrared absorption

4 Halliday D, Miller AG. Precise measurement of total body water using trace quantities of deuterium oxide. Biomed water using trace quantities
Mass Spectrom 1977;4:82-7.

5 Lifson N, Gordon GB, McClintock R. Measurement of total carbon dioxide production by means of $\mathrm{D}_{2} 0^{18} . \mathcal{F} \mathrm{Appl}$ Physiol 1955;7:704-10.

6 Culebras JM, Moore FD. Total body water and the exchangeable hydrogen. 1. Theoretical calculation of nonaqueous exchangeable hydrogen in man. Am $\mathcal{F}$ Physiol 1977;232:R54-9.

7 Van Marken Lichtenbelt WD, Westerterp KR, Wouters L Deuterium dilution as a method for determining total body water: effects of test protocol and sampling time. $\mathrm{Br}$ ₹ Nutr 1994;72:491-7.

8 Astrand P-O, Rodahl, K. Temperature regulation. In: Textbook of work physiology: physiological bases of exercise, 3rd ed. New York: McGraw-Hill, 1986.

9 Du Bois D, Du Bois EF. Clinical calorimetry. V. The measurement of surface area in man. Arch Intern Med measurement of

10 Baumer CD, Clark RG. Insensible water loss in surgical patients. Br $\mathcal{F}$ Surg 1974;61:53-6.

11 Nadel ER, Mack GW, Takamata A. Thermoregulation, exercise, and thirst: interrelationships in humans. In: Gisolfi CV, Lamb DR, Nadel ER, eds. Perspectives in exercise science and sports medicine, vol 6: Exercise, heat, and thermoregulation. Dubuque: Brown \& Benchmark, 1993:225-57. 12 Sawka MN, Greenleaf JE. Current concepts concerning
thirst, dehydration, and fluid replacement: overview. Med Sci Sports Exerc 1992;24:643-4. 